\title{
KNOWLEDGE, ATTITUDE AND PRACTICE OF PHARMACISTS AND NURSES TOWARDS ADVERSE DRUG REACTIONS- A CROSS SECTIONAL STUDY
}

\author{
Mozhgan Rahnama1, Mandana Moradi², Susan Sarhadi ${ }^{3}$ \\ ${ }_{1}^{1}$ Associate Professor, Department of Nursing, Zabol University of Medical Sciences, Zobol, Iran. \\ ${ }^{2}$ Associate Professor, Clinical Pharmacy Department School of Pharmacy, Zabol University of Medical Sciences, Zabol, Iran. \\ ${ }^{3}$ Student Research Committee, Zabol University of Medical Sciences, Zobol, Iran.
}

ABSTRACT

\section{BACKGROUND}

Drug therapy is a prerequisite in the management of different medical conditions, but one of the major concerns about it is drug related adverse effects. Pharmacovigilance is the science of conducting, assessing, understanding and preventing adverse drug reactions (ADRs). Reporting ADRs is the core of pharmacovigilance. So, this study was conducted with the aim of evaluating knowledge, attitude and practice of pharmacists and nurses about reporting ADR.

\section{METHODS}

A descriptive questionnaire-based study was carried out among 100 nurses and 15 pharmacists working in community pharmacies and Amir-Almomenin and Imam Khomeini hospitals of Zabol. The responses to KAP questionnaire were analysed by SPSS version 18.0.

\section{RESULTS}

Majority of pharmacists and nurses did not have enough knowledge about the context of pharmacovigilance, its classifications, its frequencies as well as national guidelines for reporting ADRs. We found out that the majority of our study population (60\% of pharmacists and $63 \%$ of nurses) had the experience of detecting ADR but only $13.3 \%$ of pharmacists and $22 \%$ of nurses had reported it. Reasons for not reporting ADR were as follows: being uncertain that the reaction is drug related, it's legal consequences, routine or known ADRS, being unfamiliar with the process of reporting ADRs and being too busy to report.

\section{CONCLUSIONS}

We observed that our pharmacists and nurses did not have desirable knowledge, attitude and practice towards pharmacovigilance. This fact emphasizes the importance of different corrective interventions as conducting CMEs, workshops, as well as special emphasis on pharmacovigilance in medical, pharmacy and nursing undergraduate and post graduate curriculum and its incorporation in their internship.

\section{KEY WORDS}

Adverse Drug Reactions, Pharmacists, Nurses, Pharmacovigilance

HOW TO CITE THIS ARTICLE: Rahnama M, Moradi M, Sarhadi S. Knowledge, attitude and practice of pharmacists and nurses towards adverse drug reactions- a cross sectional study. J. Evolution Med. Dent. Sci. 2019;8(22):1804-1807, DOI: $10.14260 /$ jemds/2019/396

\section{BACKGROUND}

Drug therapy is a prerequisite in management of different medical conditions, but one of the major concerns about it, is drug related adverse effects.(1) World Health Organization (WHO) describe ADR as "any noxious, unintended and undesired effect of a drug which occurs at a dose used in humans for prophylaxis, diagnosis or therapy of disease, or for the modification of physiological function."(2) As WHO guideline" the last decades it has been demonstrated by a number of studies that medicine morbidity and mortality is one of the major health problems which is beginning to be recognized by health professionals and the public. It has been estimated that such adverse drug reactions (ADRs) are the 4 th to 6th largest cause for mortality in the USA2.

'Financial or Other Competing Interest': None.

Submission 08-04-2019, Peer Review 18-05-2019,

Acceptance 23-05-2019, Published 03-06-2019.

Corresponding Author:

Mandana Moradi

Associate Professor,

Clinical Pharmacy Department School of Pharmacy,

Zabol University of Medical Sciences, Zabol, Iran.

E-mail: jahant1990@gmail.com

DOI: $10.14260 /$ jemds $/ 2019 / 396$

\section{(c) $(1) \ominus$}

They result in the death of several thousands of patients each year, and many more suffer from ADRs. The percentage of hospital admissions due to adverse drug reactions in some countries is about or more than $10 \%$. In addition, suitable services to treat ADRs impose a high financial burden on health care due to the hospital care of patients with drug related problems. Some countries spend up to $15-20 \%$ of their hospital budget dealing with drug complications. Besides ADRs, medicine-related problems include also - drug abuse, misuse, poisoning, therapeutic failure and medication errors. There is very limited information available on ADRs in developing countries and countries in transition. However, one may expect that the situation is worse rather than better. This problem is also caused by a lack, in some countries, of legislation and proper drug regulations, including ADR reporting, a large number of substandard and counterfeit products circulating in their markets, a lack of independent information and the irrational use of drugs. Since ADRs may act through the same physiological and pathological pathways as different diseases, they are difficult and sometimes impossible to distinguish. However, the following step-wise approach may be helpful in assessing possible drug-related ADRs: 1 . Ensure that the medicine ordered is the 
medicine received and actually taken by the patient at the dose advised; 2. Verify that the onset of the suspected ADR was after the drug was taken, not before and discuss carefully the observation made by the patient; 3 . Determine the time interval between the beginning of drug treatment and the onset of the event; 4. Evaluate the suspected ADR after discontinuing the drugs or reducing the dose and monitor the patient's status. If appropriate, restart the drug treatment and monitor recurrence of any adverse events. 5. Analyse the alternative causes (Other than the drug) that could on their own have caused the reaction; 6 . Use relevant up-to-date literature and personal experience as a health professional on drugs and their ADRs and verify if there are previous conclusive reports on this reaction. The National Pharmacovigilance Centre and Drug Information Centres are very important resources for obtaining information on ADR. The manufacturer of the drug can also be a resource to consult; 7. Report any suspected ADR to the person nominated for ADR reporting in the hospital or directly to the National ADR Centre".

Pharmacovigilance is a "science relating to collection, detection, assessment, monitoring and prevention of adverse effects with pharmaceutical products" and reporting ADRS is considered as a core of pharmacovigilance practice.(1,3) Since the frequency of some ADRS are very low they can just be recognized when a drug is used through a large population, by pharmacovigilance practice as part of post marketing safety monitoring studies. (4) ADRs is one of the leading cause of morbidity and mortality in healthcare settings all over the world and it is still one of the most frequent cause of death in united states. ${ }^{(5-8)}$ It is estimated that about $6.5 \%$ of all hospital admissions are related to ADRs.(3) Economic burden of ADRs is also an issue. It is estimated that about 300 million euro and 47.4 million dollars are spent annually in Germany and the U.S consecutively because of drug related problems. (7) So it is really important to study ADRS and voluntary reporting systems are available in almost all countries through yellow forms. $(7,8)$ But the problem is, just a small number of ADRs are reported all over the world, that compromise the success of pharmacovigilance practice.(8) This fact may be related to the lack of desirable knowledge, attitude and practice toward reporting ADRS in health care professionals.(9) Since we also have the problem of low ADR reports frequencies we decided to evaluate the knowledge, attitude and practice toward reporting ADRs in nurses working in tow major hospitals of city of Zabol as well as community pharmacists.

\section{METHODS}

This descriptive questionnaire-based study was conducted among 100 nurses and 15 pharmacists who were working in all 15 community pharmacies as well as Amir-Al Momenin and Imam Khomeini hospitals of city of Zabol. This study was approved by Zabol University of medical sciences. A verbal consent of the participants was taken before enrolling the study. Questionnaire was designed to obtain demographic data like age, gender degree of education and their history about participation in any course or conference about pharmacovigilance. KAP questionnaire was designed based on standard questionnaire by pharmacovigilance in European Union. This was also used in two previous studies by
Salehifar. et al (2007) and Ghasemian. et al 2006 and its reliability and validity were approved.(7,8)

\begin{tabular}{|c|c|c|c|}
\hline Parameter & \multicolumn{2}{|c|}{ Pharmacists } & Nurses \\
\hline Age[ years; mean (SD)] & \multicolumn{2}{|c|}{$36.73(5.59)$} & $35.75(6.88)$ \\
\hline \multirow{2}{*}{ Gender [N (\%)] } & Male & $10(66.7)$ & $32(32)$ \\
\cline { 2 - 4 } & Female & $5(33.3)$ & $68(68)$ \\
\hline \multirow{3}{*}{ Educational level } & Bachelor & 0 & $100(100)$ \\
\cline { 2 - 4 } & Master & 0 & 0 \\
\cline { 2 - 4 } & Doctorate & $8(53.3)$ & 0 \\
\cline { 2 - 4 } & Ph. D & $7(46.7)$ & 0 \\
\hline
\end{tabular}

Table 1. Demographic Characteristics of Study Population

\begin{tabular}{|c|c|c|c|}
\hline & Question & $\begin{array}{l}\text { Pharma } \\
\text { cists [N of } \\
\text { Correct } \\
\text { Answers } \\
(\%)] \\
\end{array}$ & $\begin{array}{l}\text { Nurses } \\
\text { [N of } \\
\text { Correct } \\
\text { Answers } \\
(\%)] \\
\end{array}$ \\
\hline $\begin{array}{l}\text { Definition of } \\
\text { pharmaco- } \\
\text { vigilance }\end{array}$ & \begin{tabular}{|c|} 
Pharmacovigilance is the \\
since of detecting, reporting, \\
evaluating and treating \\
ADRs or any drug related \\
problem
\end{tabular} & $0(0)$ & $1(1)$ \\
\hline \multirow{6}{*}{$\begin{array}{l}\text { National } \\
\text { guidelines for } \\
\text { reporting ADRs }\end{array}$} & $\begin{array}{l}\text { Reports about all suspected } \\
\text { ADRs are registered in any } \\
\text { pharmacovigilance system }\end{array}$ & $0(0)$ & $11(11)$ \\
\hline & $\begin{array}{c}\text { Pharmacovigilance evaluate } \\
\text { adverse effects of synthetic } \\
\text { drugs }\end{array}$ & $12(80)$ & 38 ( 38$)$ \\
\hline & $\begin{array}{c}\text { Adverse effects of any } \\
\text { herbal or traditional } \\
\text { medicine is also evaluated } \\
\text { in pharmacovigilance }\end{array}$ & $13(86.7)$ & $29(29)$ \\
\hline & $\begin{array}{c}\text { Drug abuse and drug in } \\
\text { pregnancy and lactation is } \\
\text { also discussed in } \\
\text { pharmacovigilance }\end{array}$ & $11(73.3)$ & $66(66)$ \\
\hline & $\begin{array}{l}\text { Reports about decreasing } \\
\text { efficacy, drug resistance and } \\
\text { counterfeit drugs are also } \\
\text { evaluated by } \\
\text { pharmacovigilance centers }\end{array}$ & $10(66.7)$ & $33(33)$ \\
\hline & $\begin{array}{c}\text { Adverse effects of cosmetics } \\
\text { are also evaluated by } \\
\text { pharmacovigilance centers }\end{array}$ & $10(66.7)$ & $30(30)$ \\
\hline \multirow{4}{*}{$\begin{array}{l}\text { Frequency of } \\
\text { ADRs }\end{array}$} & \begin{tabular}{|c|} 
Common \\
\end{tabular} & $1(6.7)$ & $14(14)$ \\
\hline & Uncommon & $1(6.7)$ & $20(20)$ \\
\hline & Rare & $6(40)$ & $20(20)$ \\
\hline & Very rare & $3(20)$ & $23(23)$ \\
\hline \multicolumn{4}{|c|}{ Table 2. Knowledge of Pharmacists and Nurses } \\
\hline
\end{tabular}

\begin{tabular}{|c|c|c|}
\hline Mentioned Reasons & $\begin{array}{c}\text { Pharmacists } \\
\text { N (\%) }\end{array}$ & $\begin{array}{c}\text { Nurses } \\
\text { N (\%) }\end{array}$ \\
\hline $\begin{array}{l}\text { Being suspicions about the } \\
\text { accuracy of ADR }\end{array}$ & $5(33.3)$ & $29(29)$ \\
\hline Mild ADRs & $2(13.3)$ & $23(23)$ \\
\hline Known ADRs & $4(26.7)$ & $19(19)$ \\
\hline $\begin{array}{l}\text { Lack of enough knowledge about the } \\
\text { importance of reporting ADR }\end{array}$ & $1(6.7)$ & $6(6)$ \\
\hline Being unfamiliar with reporting procedures & $8(53.4)$ & 17 (17) \\
\hline Being busy & $11(73.4)$ & $81(81)$ \\
\hline Concerns about its consequence & $2(13.3)$ & $8(8)$ \\
\hline \multicolumn{3}{|c|}{ Table 3. Mentioned Reasons for not Reporting ADRs } \\
\hline
\end{tabular}

\begin{tabular}{|c|c|c|c|}
\hline \multicolumn{2}{|c|}{} & $\begin{array}{c}\text { Pharmacists N } \\
(\mathbf{\%})\end{array}$ & $\begin{array}{c}\text { Nurses N } \\
(\mathbf{\%})\end{array}$ \\
\hline \multicolumn{2}{|c|}{ History of detecting ADR } & $9(60)$ & $63(63)$ \\
\hline \multicolumn{2}{|c|}{ History of reporting ADR } & $2(13.3)$ & $22(22)$ \\
\hline \multirow{2}{*}{$\begin{array}{c}\text { Where to } \\
\text { report } \\
\text { ADR }\end{array}$} & National ADR center & $0(0)$ & $0(0)$ \\
\cline { 2 - 4 } & Pharmaceutical industry & $2(13.1)$ & $1(1)$ \\
\cline { 2 - 4 } & Hospital related center & $0(0)$ & $21(21)$ \\
\hline
\end{tabular}

Table 4. Practice of Study Population About Reporting ADRs 
The knowledge base questions assessed knowledge regarding various aspects of pharmacovigilance such as type of ADRS that should be reported and classifications of ADRs as well as who can report ADRs. The attitude-based questions assessed the view of the participants regarding toward obligation about reporting ADRs in different situations epically about Over the Counter (OTC) drugs. The practicebased questions assessed the rate of reporting ADRs and the process of reporting.(8) After a brief description about the purpose of the study the questionnaire was distributed to each participant with about 30-minute time to fill it. Data collected was analysed using the Statistical Package for Social Silences software (SPSS) version 18 using descriptive frequency method. $\mathrm{P}$ value $<0.05$ were defined statistically significant.

\section{RESULTS}

The demographic details of study population are shown in table 1 . The mean age of pharmacists and nurses were 36.73 (5.59) and 35.75 (6.88). The majority of pharmacists were men $(66.7 \%)$ while female accounted the majority of nurses (68\%). None of pharmacists had the experience of pharmacovigilance education but $14 \%$ of nurses claimed they had attended in some sort of educational courses about pharmacovigilance.

Responses to different questions related to the knowledge showed that the majority of pharmacists and nurses did not have enough knowledge about the context of pharmacovigilance and its classifications and frequencies as well as national guidelines for reporting ADRs (Table 2).

Exploring their attitude toward pharmacovigilance and reporting ADRs showed that although, $33.3 \%$ of pharmacists and $37 \%$ of nurses remembered suspected cases of ADRs in their carrier, but they had never reported them. The most important reasons described by pharmacists for not reporting these cases were; being uncertain that the reaction is drug related, it's legal consequences, routine or known ADRS, not being familiar with the process of reporting ADRs, and being too busy to report.

The most important reasons described by nurses were as follows; being too busy too report and not being certain about the accuracy of drug related adverse effects (Table 3).

Regarding the result related their practice toward pharmacovigilance we found out that the majority of our study population ( $60 \%$ of pharmacists and $63 \%$ of nurses) had the experience of detecting ADR but only $13.3 \%$ of pharmacists and $22 \%$ of nurses had reported it. They also claimed that they reported their observations to their hospital centers. Details are described in table 4.

\section{DISCUSSION}

In the present study the majority of nurses and pharmacists lack sufficient knowledge about pharmacovigilance, national reporting guidelines, classification and frequency of ADRs.

Results of similar KAP study by Salehifaret.al showed the same results (8). Lack of enough knowledge about pharmacovigilance in pharmacists were also reported by other researchers (10-15). On the other hand, Ganesan et.al. showed that the majority of nurses had desirable knowledge about importance of ADR monitoring.(5) This difference may be related to different study population, setting and methods of study.
We also observed that although the majority of pharmacists and nurses had the history of detecting various cases of ADRs but only small number of them were reported. Salehifar et.al. also observed although more than $80 \%$ of their study population had observed cases of ADRs in their practice but only $10 \%$ of them had reported these cases. They concluded that maybe the consequence of poor attitude about reporting ADRs.(8) This results were consistent with a previous report by Toklu et al that although $89 \%$ of pharmacists accepted the importance of their role in reporting ADRs but only $7 \%$ of them were actively involved in reporting ADRs to national center of pharmacovigilance.(13) About half of pharmacists involved in Vessal study also did not reported suspected ADRs.(11) It was reported in other studies that although pharmacists had positive attitude toward pharmacovigilance but they did not show desirable practice in reporting ADRs(14) Gensen et al also showed that nurses involved in their study did not have enough knowledge about importance of reporting ADRs. It is worth to notice that nurses can have a crucial role in reporting ADRS as they are directly involved in drug administration and patient care.(8)

Considering the small number of pharmacists and nurses who had enrolled in pharmacovigilance workshop our study highlighted the importance of pharmacovigilance education. This fact was also emphasized in other studies by conducting pharmacovigilance workshops, and changing undergraduate pharmacy curriculum with more ADRs monitoring and reporting aspects. $(8,10,11,12,13,14,15)$

Both pharmacists and nurses mentioned same reasons for not reporting ADR, but with different frequencies, as follows: known ADR, being unfamiliar with reporting procedures, being too busy to report ADR, being concerned about the consequences of reporting ADR, mild ADR and being suspicious that case is drug related that was consistent with Salehi far et al results.(8) Study conducted by Vesal et al showed being uncertain and unfamiliar with their responsibilities for reporting ADRs as contributing factors. (11) Inadequate information available from the patients, unavailability of ADRs forms, unawareness of the existence of national ADR reporting system were also reported as discouraging factors for reporting ADRs in pharmacists by other studies. (14) Ganesan et al showed that ADR reporting can be further increased by improving access to ADR reporting forms.(5) Most explained reasons in other studies are similar to ours and indicate need for multidisciplinary interventions to promote ADR reporting culture.

\section{CONCLUSIONS}

We observed that our pharmacists and nurses did not have desirable knowledge, attitude and practice toward pharmacovigilance. This fact can be related to inadequate reporting culture among healthcare professionals. The reporting rate could be improved by easy access to yellow cards, activation of an ADR center in hospitals, considering motivational interventions for healthcare professionals, training activities through CMEs or workshops as well as special emphasis on pharmacovigilance in medical, pharmacy and nursing undergraduate and post graduate curriculum and its incorporation in their internship. 


\section{REFERENCES}

[1] Rajesh B, Devangi DR, Waseem A. Assessment of knowledge, attitude and practice of pharmacovigilance among doctors practicing alternative systems of medicine in Southern India: a questionnaire-based study. National Journal of Phisiology, Pharmacy and Pharmacology 2017;7(1):119-22.

[2] Beedimani R, Uz Zaman S, Darbha S, et al. An evaluation of Knowledge, attitude and practice of pharmacovigilance among medical students and doctors at tertiary care hospital. International Journal of Basic \& Clinical Pharmacology 2018;7(2):324-32.

[3] Tadvi NA, Alromaih AA, Aldahash AA, et al. Knowledge, attitude and practice of pharmacovigilance in healthcare professionals and medical students in Majmaah, Saudi Arabia Care Centre. International Journal of Medical Research \& Health Sciences 2018;7(4):101-7.

[4] Katekhaye VM, Kadhe NG, John J, et al. Knowledge, attitude and practice of pharmacovigilance among medical professional at a tertiary care hospital in Mumbai, Maharashtra, India. International Journal of Research in Medical Sciences 2017;5(1):156-61.

[5] Ganesan S, Vikneswaran G, Reddy KC, et al. A survey on knowledge, attitude and practice of pharmacovigilance towards adverse drug reactions reporting among doctors and nurses in tertiary care hospital in South India. J Young Pharm 2016;8(4):4716.

[6] Gupta SK, Nayak RP, Shivaranjani R, et al. A questionnaire study on the knowledge, attitude and thr practice of pharmacovigilance among the health care professionals in a teaching hospital in South India. Perspect Clin Res 2015;6(1):45-52.

[7] Ghasemian R, Mahmoudi M, Khalilian AR. Physicians' knowledge, attitude and performance regarding adverse drug reaction and its reporting in Sari. Journal of Mazandaran University of Medical Sciences 2004;15(50):97-104.
[8] Salehifar E, Ala SH, Gholami KH. Knowledge, attitude and performance of pharmacists and nurses in Mazandaran province, Iran regarding advers drug reaction and its reporting, 2005. Journal of Mazandaran University of Medical Sciences 2007;16(56):115-25.

[9] Dhananjay K, Himasri E. A study of assessing knowledge, attitude and practice of pharmacovigilance among medical students of a South India teaching hospital. International Journal of Basic \& Clinical Pharmacology 2017;6(1):43-7.

[10] Khobrani AA, Almalki MS, Alotaibi FT, et al. Pharmacist's Knowledge, practice and attitudes toward pharmacovigilance and adverse drug reactions. The Egyption Journal of Hospital Medicine 2018;70(7):1224-7.

[11] Vessal G, Mardani Z, Mollai M. Knowledge, attitude and perception of pharmacists to adverse drug reaction reporting in Iran. Pharm World Sci 2009;31(2):183-7.

[12] Kiran PG, Anil SP. A cross sectional pilot study of Knowledge, attitude and practice of pharmacovigilance among pharmacists at Rajkot district. Journal of Basic and Clinical Pharmacy 2017;8(Special Issue):S20-S3.

[13] Toklu HZ, Uysal MK. The Knowledge and attitude of Turkish community pharmacists toward pharmacovigilance in the Kadikoy district of Istanbul. Pharm World Sci 2008;30(5):556-62.

[14] Suyagh M, Farah D, Farah RA. Pharmacist's knowledge, practice and attitudes toward pharmacovigilance and adverse drug reactions reporting process. Saudi Pharmaceutical Journal 2015;23(2):147-53.

[15] Isfahani EM, Mousavi S, Rakhshan A, et al. Adverse drug reactions: knowledge, attitude and practice of pharmacy students. Journal of Pharmaceutical Care 2013;1(4):145-8. 